\title{
Complex Formation by Positive and Negative Translational Regulators of GCN4
}

\author{
A. MARK CIGAN, MARCO FOIANI, ERNEST M. HANNIG, $\dagger$ AND ALAN G. HINNEBUSCH* \\ Section on Molecular Genetics of Lower Eukaryotes, Laboratory of Molecular Genetics, National Institute of \\ Child Health and Human Development, Bethesda, Maryland 20892
}

Received 18 January 1991/Accepted 27 March 1991

\begin{abstract}
GCN4 is a transcriptional activator of amino acid biosynthetic genes in Saccharomyces cerevisiae whose expression is regulated by amino acid availability at the translational level. GCD1 and GCD2 are negative regulators required for the repression of $G C N 4$ translation under nonstarvation conditions that is mediated by upstream open reading frames (uORFs) in the leader of GCN4 mRNA. GCD factors are thought to be antagonized by the positive regulators GCN1, GCN2, and GCN3 in amino acid-starved cells to allow for increased GCN4 protein synthesis. Previous genetic studies suggested that GCD1, GCD2, and GCN3 have closely related functions in the regulation of $G C N 4$ expression that involve translation initiation factor 2 (eIF-2). In agreement with these predictions, we show that GCD1, GCD2, and GCN3 are integral components of a high-molecular-weight complex of approximately 600,000 Da. The three proteins copurified through several biochemical fractionation steps and could be coimmunoprecipitated by using antibodies against GCD1 or GCD2. Interestingly, a portion of the eIF-2 present in cell extracts also cofractionated and coimmunoprecipitated with these regulatory proteins but was dissociated from the GCD1/GCD2/GCN3 complex by $0.5 \mathrm{M} \mathrm{KCl}$. Incubation of a temperature-sensitive $\mathrm{gcdl}$-101 mutant at the restrictive temperature led to a rapid reduction in the average size and quantity of polysomes, plus an accumulation of inactive $80 \mathrm{~S}$ ribosomal couples; in addition, excess amounts of eIF-2 $\alpha$, GCD1, GCD2, and GCN3 were found comigrating with free $40 S$ ribosomal subunits. These results suggest that GCD1 is required for an essential function involving eIF-2 at a late step in the translation initiation cycle. We propose that lowering the function of this high-molecular-weight complex, or of eIF-2 itself, in amino acid-starved cells leads to reduced ribosomal recognition of the uORFs and increased translation initiation at the GCN4 start codon. Our results provide new insights into how general initiation factors can be regulated to affect gene-specific translational control.
\end{abstract}

The GCN4 protein of the yeast Saccharomyces cerevisiae is a transcriptional activator of amino acid biosynthetic genes that are subject to general amino acid control. Transcription of these genes is stimulated by GCN4 in response to starvation for any amino acid. The expression of GCN4 itself is regulated by amino acid availability, but at the translational level. Four short open reading frames (uORFs) in the long leader sequence of GCN4 mRNA function as cis-acting regulatory elements that couple the rate of $G C N 4$ translation to amino acid levels. Under nonstarvation conditions, the uORFs restrict scanning ribosomes from reaching the GCN4 start codon; in amino acid-starved cells, this translational barrier is overcome, leading to increased GCN4 protein synthesis (reviewed in reference 26).

Multiple trans-acting factors have also been implicated in translational control of $G C N 4$ expression. $G C D$ genes were defined genetically as negative regulatory factors that are required for the inhibitory effects of the uORFs under nonstarvation conditions; consequently, gcd mutations lead to constitutively derepressed GCN4 expression. The temperature-sensitive growth on rich medium associated with gcd mutations, combined with the fact that deletions of $G C D 1$ or $G C D 2$ are unconditionally lethal $(24,38)$, shows that GCD1 and GCD2 carry out essential functions in addition to their roles as translational repressors of GCN4. There are some indications that the essential function of

\footnotetext{
* Corresponding author.

$\dagger$ Present address: Department of Molecular and Cell Biology, The University of Texas at Dallas, Richardson, TX 75083-0688.
}

GCD1 is involved in protein synthesis. Strains containing the gcdl-101 mutation are temperature sensitive for the incorporation of radiolabeled amino acids into proteins in vivo $(24,53)$, although DNA and RNA synthesis also appear to be affected with similar kinetics (53). In addition, after an extended incubation at $37^{\circ} \mathrm{C}, g c d 1-101$ cells were found to be depleted for $40 \mathrm{~S}$ initiation complexes containing charged tRNA ${ }_{i}^{\text {Met }}$ (49).

Consistent with the idea that GCD factors have general functions in translation, it was found that certain mutations affecting the yeast translation initiation factor 2 (eIF-2) affect GCN4 expression in the same way as do gcd mutations. eIF-2 is a multimeric protein complex of approximately 125,000 Da containing three nonidentical subunits, $\alpha\left(M_{\mathrm{r}}=\right.$ $36,100), \beta\left(M_{\mathrm{r}}=38,000\right)$, and $\gamma\left(M_{\mathrm{r}}=55,300\right)$ (33). During the early steps of translation initiation, eIF-2 forms a ternary complex with GTP and the initiator tRNA ${ }_{i}^{\text {Met }}$ that interacts with the $40 \mathrm{~S}$ ribosomal subunit to form a $43 \mathrm{~S}$ preinitiation complex. This intermediate binds to the 5' end of mRNA and scans the leader until an AUG codon is reached. GTP is then hydrolyzed, and eIF-2 is released from the small ribosomal subunit as a binary complex with GDP. After joining of the $60 \mathrm{~S}$ ribosomal subunit to form an $80 \mathrm{~S}$ initiation complex, the elongation cycle begins (33). Mutations in SUI2 and SUI3, encoding the $\alpha$ and $\beta$ subunits of yeast eIF-2, respectively, were isolated for their ability to restore expression to a his 4 allele lacking an AUG start codon $(8,12)$. Interestingly, these mutations were also found to cause derepression of GCN4 translation under nonstarvation conditions. As with mutations in $G C D$ genes, the $S U I$ mutations were dependent on the GCN4 uORFs for their derepressing effects, and they 
bypassed the requirement for the positive regulator GCN2 for high-level GCN4 expression. Thus, in addition to its general role in AUG start site selection, yeast eIF-2 may be important in the regulation of $G C N 4$ translation by amino acid availability.

In contrast to $G C D$ genes, $G C N 1, G C N 2$, and $G C N 3$ encode positive factors required to overcome the inhibitory effects of the uORFs; thus, mutations in these genes impair derepression of GCN4 expression under starvation conditions. Because $g c d$ mutations lead to constitutive derepression of $G C N 4$ expression in the absence of $G C N 1, G C N 2$, or $G C N 3$, these three positive effectors are thought to antagonize the function of GCD factors in amino acid-starved cells (26). Genetic and molecular data suggest that among these three positive regulators, GCN3 interacts most closely with the GCD factors. Two gcd 2 mutations were isolated that overcome the low-level GCN4 expression associated with a gcn3-101 mutation, producing a constitutively derepressed $\left(\mathrm{Gcd}^{-}\right)$phenotype. These $g c d 2$ alleles (originally designated gcd12) also lead to temperature-sensitive growth on rich medium $(22,38)$. Surprisingly, neither the growth defect nor the derepression of $G C N 4$ expression associated with these $\operatorname{gcd} 2$ mutations is expressed in $\operatorname{gcd} 2 \mathrm{GCN} 3$ strains, suggesting that $G C N 3$ can restore the essential and negative regulatory functions of $G C D 2$ impaired in these $g c d 2$ mutants. Similar results were obtained for a group of $\mathrm{gcdl}$ mutations that were also isolated as suppressors of gcn3-101 (21). In addition to these genetic interactions, there is significant amino acid sequence similarity between GCN3 and the carboxyl-terminal half of GCD2, suggesting that these two proteins have similar functions. This structural similarity could explain the ability of $G C N 3$ to complement certain gcd2 mutations by a functional replacement mechanism (37). Alternatively, GCN3 might physically interact with GCD2 (and GCD1), enabling it to stabilize thermolabile $g c d$ products under nonstarvation conditions $(21,37)$.

Like mutations in $G C D 1$ and $G C D 2$, the temperaturesensitive sui2-1 mutation in the alpha subunit of eIF-2 is unconditionally lethal in combination with a deletion of GCN3 (52). The fact that mutations affecting the $\alpha$ and $\beta$ subunits of eIF-2 also resemble $g c d$ mutations in derepressing GCN4 translation suggests that GCD1, GCD2, and GCN3 are functionally associated with eIF-2. This notion receives strong support from the results presented below showing that GCD1, GCD2, and GCN3 are integral components of a high-molecular-weight complex that appears to be physically associated with subunits of the eIF-2 complex. All of these factors were found to comigrate with $40 \mathrm{~S}$ ribosomal subunits when translation initiation was specifically impaired in vivo by the gcdl-101 mutation, suggesting that the GCD1containing complex is involved in the formation or utilization of $43 \mathrm{~S}$ preinitiation intermediates.

\section{MATERIALS AND METHODS}

Yeast strains and plasmids. The wild-type strains $\mathrm{H} 4$ (MATa leu2-3, 112 ura3-52) and TD28 (MATa ura3-52 inol13) and the temperature-sensitive mutant F98 (MAT $\alpha$ ura3-52 gcd1-101) were derived from S288C and have been used extensively for the analysis of general amino acid control and the study of protein synthesis in yeast cells $(8$, $12,20,35,36)$. Yeast strain 117-8AR20 was described previously (8) and was kindly provided by Thomas Donahue. MC1017 was generated by transforming (28) strain H4 with the high-copy-number URA3-containing yeast vector YEp24 (39). Strains EY412 and MC1019 were made by transforming
H4 with plasmids Ep256 and CR52, respectively. Plasmid Ep256 contains the 2.4-kb GCD1 BamHI fragment, isolated from plasmid Sc4014 (24) and inserted into the BamHI site of YEp24; CR52 contains an 8.0-kb HindIII fragment encompassing the $P R T 1$ gene (18) inserted into the HindIII site of the high-copy-number $U R A 3$-containing yeast vector YEp352 (39). Standard genetic techniques and media used for these studies have been described previously (43).

The wild-type GCDI strain MC1001 was constructed from F98 by gene replacement using plasmid YIp5-Sc4040 (24), containing the wild-type GCDI gene on a $3.8-\mathrm{kb}$ BamHI fragment. The plasmid was digested at the $B g$ III site in the $G C D l$ coding region and used to transform F98 to $\mathrm{Ura}^{+}(27)$. Beginning with $\mathrm{Ura}^{+}$temperature-resistent transformants, we selected for loss of the plasmid by the 5-fluoro-orotic acid-positive selection procedure (4). $\mathrm{Ura}^{-}$colonies were purified and screened for the temperature-resistant phenotype indicative of replacement of the gcdl-101 allele with wild-type $G C D 1$.

Antiserum production and characterization. Antibodies directed against the $G C D I$ and $P R T 1$ gene products were generated from $\operatorname{trp} E-G C D 1$ and $\operatorname{trpE-PRT1}$ fusion proteins, respectively, that were expressed in Escherichia coli. To generate the $\operatorname{trpE-GCDI}$ fusion, the $G C D I$ coding region from amino acid positions +34 to +511 , contained on the 1.9-kb PvuII-BamHI fragment isolated from plasmid Sc4014 (24), was ligated in frame to the carboxyl end of the $E$. coli $\operatorname{trp} E$ coding region in the $\mathrm{pATH} 3$ vector (11). The trpE-PRTI fusion was constructed by ligating the 2.6-kb XbaI-ClaI fragment, which contains the distal region of the $P R T I$ coding region from amino acid positions +227 to $+763(18)$, in frame to the carboxyl end of $\operatorname{trpE}$ in the pATH3 vector. The methods used to isolate the fusion protein and immunize rabbits have been described previously (12).

The specificities and titers of these antisera were determined by immunoblot analysis (47) of total cell extracts, comparing the aforementioned yeast strains MC1017, EY412, and MC1019 that contain GCDI or PRTl genes in single or high copy number. Yeast cell extracts were prepared as previously described (12) except that cells were grown selectively in synthetic dextrose medium lacking uracil. Samples of extracts were electrophoresed through 8.0 or $10 \%$ sodium dodecyl sulfate (SDS)-polyacrylamide gels (30), and the proteins were transferred to nitrocellulose filters by using Towbin buffer (47) containing $0.1 \%$ SDS. The filters were incubated with a blocking solution consisting of $4 \%$ nonfat dry milk in Tris-buffered saline (TBS; $50 \mathrm{mM}$ Tris- $\mathrm{HCl}[\mathrm{pH} 7.5], 150 \mathrm{mM} \mathrm{NaCl}$ ) and $0.2 \%$ Triton $\mathrm{X}-100$. Filters were incubated with the primary antibody (see figure legends for dilutions) in the presence of blocking solution overnight at room temperature and then washed five times with $200 \mathrm{ml}$ of TBS. The antigen-antibody complexes were detected by using either a strepavidin-alkaline phosphatase conjugate system (Bio-Rad) or ${ }^{125} \mathrm{I}$-protein $\mathrm{A}(30 \mathrm{mCi} / \mathrm{mg}$ of protein A; Amersham) according to the vendor's instructions.

As shown in Fig. 1A, polyclonal antisera directed against the $\operatorname{trp} E-G C D I$ fusion protein specifically cross-reacted with a protein present in yeast crude extracts with an apparent $M_{\mathrm{r}}$ value of 65,000 that was more abundant when $G C D 1$ was present on a high-copy-number plasmid. Based on a previously published DNA sequence, the $G C D 1$ open reading frame would produce a 511-amino-acid polypeptide with a calculated $M_{\mathrm{r}}$ value of only 57,569 (24). DNA sequence analysis of the GCDI gene resolved this discrepancy between the predicted and observed $M_{\mathrm{r}}$ values in showing that 


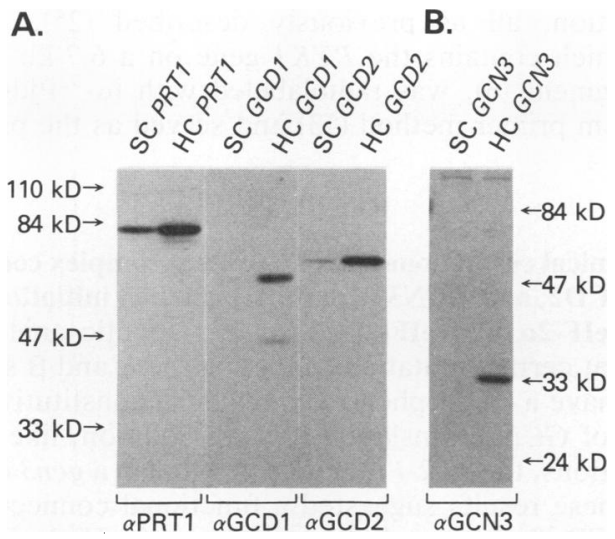

FIG. 1. Immunoblot analysis of protein extracts from yeast transformants containing single or high-copy-number $P R T 1, G C D 1$, $G C D 2$, or $G C N 3$ genes. Samples $(50 \mu \mathrm{g})$ of crude extracts from strain MC1017 containing all four genes in single copy (SC lanes) and from four isogenic strains containing each gene on a high-copynumber plasmid (HC lanes [HC PRT1, MC1019; HC GCD1, EY412; HC GCD2, H1388; HC GCN3, EY263]) were electrophoresed on $10 \%$ (A) or $8 \%$ (B) SDS-polyacrylamide gels along with prestained molecular weight markers (Bio-Rad Laboratories). Positions of the molecular weight markers are indicated by arrows. Proteins were transferred to nitrocellulose filters and probed separately with antibodies against PRT1 ( $\alpha$ PRT1; 1:300 dilution), GCD1 ( $\alpha$ GCD1; 1:300 dilution), GCD2 ( $\alpha \mathrm{GCD} 2 ; 1: 500$ dilution), and GCN3 ( $\alpha \mathrm{GCN} 3$; 1:50 dilution) in blocking solution overnight at room temperature. Immune complexes were detected by incubating the filter with ${ }^{125} \mathrm{I}$-protein $\mathrm{A}$ at a final concentration of $0.1 \mu \mathrm{Ci} / \mathrm{ml}$ in blocking solution for $2 \mathrm{~h}$, washing it in TBS, and exposing it to X-ray film at $-70^{\circ} \mathrm{C}$ using an intensifying screen.

the $G C D 1$ coding region extends an additional 68 amino acids from the carboxyl end of the previously published sequence and thus encodes a 579-amino-acid polypeptide with a calculated $M_{\mathrm{r}}$ value of $65,764(6 \mathrm{a})$.

The $P R T 1$ gene encodes a 763-amino-acid polypeptide with a predicted $M_{r}$ value of 88,137 (18). As shown in Fig. $1 \mathrm{~A}$, antibodies directed against the $\operatorname{trpE-PRTI}$ fusion protein detected an immunoreactive polypeptide in yeast crude extracts with an apparent $M_{\mathrm{r}}$ value of 87,000 that was more abundant when $P R T I$ was present on a high-copy-number plasmid.

The deduced amino acid sequences of GCD2 and GCN3 correspond to polypeptides with calculated $M_{\mathrm{r}}$ values of 70,851 and 34,024 , respectively. The generation and characterization of antibodies specific for these proteins have been described (14a, 19). As shown in Fig. 1, the anti-GCD2 and anti-GCN3 antisera. specifically cross-reacted with proteins of the expected $M_{\mathrm{r}}$ values of 70,000 and 33,000, respectively, that were more abundant when the corresponding genes were present on high-copy-number plasmids. Antibodies specific for the $\alpha$ and $\beta$ subunits of eIF-2 have been described previously $(8,12)$ and were kindly provided by Thomas Donahue at the University of Indiana.

Coimmunoprecipitation experiments. Protein A-agarose beads (Boehringer Mannheim) were resuspended in an equal volume of nondenaturing binding buffer $(20 \mathrm{mM}$ Tris- $\mathrm{HCl}$ [pH 7.5], $50 \mathrm{mM} \mathrm{KCl}, 0.1 \%$ Triton X-100, $1 \mathrm{mM}$ phenylmethylsulfonyl fluoride, $0.7 \mu \mathrm{g}$ of pepstatin A per ml). Thirty microliters of GCD1-specific or GCD2-specific antiserum was incubated with $25 \mu \mathrm{l}$ of the protein A-agarose bead suspension and $200 \mu \mathrm{l}$ of binding buffer for $2 \mathrm{~h}$ at room temperature. The beads were pelleted by centrifugation in a microfuge for 5 to $10 \mathrm{~s}$ and washed three times with $300 \mu \mathrm{l}$ of binding buffer. Various protein extracts from strain TD28, prepared as described below, were added, and the total volume of each sample was brought to $200 \mu$ l with binding buffer. The reaction mixtures were incubated at $4^{\circ} \mathrm{C}$ for 2 to $3 \mathrm{~h}$ with rocking, after which proteins bound to the protein $\mathrm{A}$ beads were pelleted and washed as above and then resuspended in $200 \mu \mathrm{l}$ of Laemmli sample buffer (30). The proteins remaining in each supernatant fraction were precipitated by the addition of trichloroacetic acid (TCA) to $10 \%$, pelleted in a microfuge, washed twice with $300 \mu$ lof ice-cold acetone, dried, and resuspended in $200 \mu$ l of Laemmli sample buffer. The pellet and supernatant fractions were electrophoresed on $10 \%$ SDS-polyacrylamide gels and analyzed by immunoblotting.

Biochemical fractionation. The GCD1, GCD2, and GCN3 proteins were partially purified from the wild-type strain TD28 by a modification of a previously published procedure (12). Fractionation of these proteins, as well as eIF-2 $\alpha$, eIF-2 $\beta$, and PRT1, was monitored by immunoblot analysis. Cells (10 liters) were grown at $25^{\circ} \mathrm{C}$ in YEPD to an optical density at $600 \mathrm{~nm}\left(\mathrm{OD}_{600}\right)$ of 1.4 to 1.5 . Samples (40 to $60 \mathrm{~g}$ ) of cells were harvested, washed with 2 liters of ice cold double-distilled $\mathrm{H}_{2} \mathrm{O}$, and resuspended at $2 \mathrm{ml} / \mathrm{g}$ of cells in lysis buffer (20 mM Tris- $\mathrm{HCl}$ [pH 7.5], $100 \mathrm{mM} \mathrm{KCl,} 30 \mathrm{mM}$ $\mathrm{MgSO}_{4}, 1 \mathrm{mM}$ dithiothreitol) containing protease inhibitors (1 $\mathrm{mM}$ phenylmethyl sulfonyl fluoride, pepstatin A [0.7 $\mu \mathrm{g} / \mathrm{ml}$ ], leupeptin, $[1 \mu \mathrm{g} / \mathrm{ml}]$, aprotinin $[1 \mu \mathrm{g} / \mathrm{ml}])$. Cells were broken with glass beads $(0.44-\mathrm{mm}$ diameter) in a Bead Beater for $4 \mathrm{~min}$ on ice. Extracts were cleared by two sequential centrifugation steps $(5,000 \times g$ for $5 \mathrm{~min}$ and $22,000 \times g$ for $15 \mathrm{~min}$ ), and ribosomes were pelleted at $200,000 \times g$ for $2 \mathrm{~h}$. The ribosomal pellets were resuspended in lysis buffer containing $500 \mathrm{mM} \mathrm{KCl}(0.25 \mathrm{ml} / \mathrm{g}$ of starting cell weight) and centrifuged for $2 \mathrm{~h}$ at $200,000 \times g$. The supernatants were dialyzed overnight at $4^{\circ} \mathrm{C}$ against 2 liters of dialysis buffer ( $20 \mathrm{mM}$ Tris- $\mathrm{HCl}$ [pH 7.5], $100 \mathrm{mM} \mathrm{KCl}, 2$ $\mathrm{mM} \mathrm{MgCl}_{2}$ ) containing the protease inhibitors indicated above. Typically, $1.5 \mathrm{ml}$ of the ribosomal salt wash (RSW) containing 5 to $15 \mathrm{mg}$ of protein was loaded on a Sephacryl S-300 HR sizing column (1.5 by $46 \mathrm{~cm}$; Pharmacia) equilibrated with dialysis buffer, and 1-ml fractions were collected. The fractions containing the majority of the coeluting GCD1, GCD2, and GCN3 were pooled and applied directly to a DEAE Sephacyl CL-6B column ( 1.5 by $5 \mathrm{~cm}$; Pharmacia) equilibrated with DEAE column buffer (dialysis buffer containing $10 \%$ glycerol). Proteins were eluted from the DEAE column by a $50-\mathrm{ml} 0.1$ to $1.0 \mathrm{M} \mathrm{KCl}$ linear salt gradient in DEAE buffer, and 2-ml fractions were collected. The peak fractions (eluting at approximately 300 to $400 \mathrm{mM}$ $\mathrm{KCl}$ ) containing the coeluting GCD1, GCD2, and GCN3 were concentrated and dialyzed against gradient buffer (20 $\mathrm{mM}$ Tris- $\mathrm{HCl}$ [pH 7.5], $100 \mathrm{mM} \mathrm{KCl,} 1 \mathrm{mM}$ dithiothreitol) containing $10 \%$ glycerol and protease inhibitors, using a Centricon-30 (Amicon). This material was centrifuged at $4^{\circ} \mathrm{C}$ in an SW41 rotor either at 27,500 rpm for $24 \mathrm{~h}$ in 15 to $30 \%$ sucrose gradients equilibrated in gradient buffer or at 39,000 rpm for $25 \mathrm{~h}$ in low- or high-salt 15 to $40 \%$ glycerol gradients equilibrated in gradient buffer and gradient buffer containing $500 \mathrm{mM} \mathrm{KCl}$, respectively. Gradients were fractionated and scanned at $280 \mathrm{~nm}$ in an ISCO gradient collector by displacement from the bottom of the tubes with $60 \%$ sucrose or glycerol; 0.6-ml fractions were collected. By comparing signal intensities of GCD1, GCD2, GCN3, eIF- $2 \alpha$, and eIF- $2 \beta$ on immunoblots between the low-salt glycerol gradi- 
ent fractions 13 and 14 (containing the peak of cofractionating GCD1, GCD2, and GCN3) and the crude extract, we estimate a 2,000-fold purification of these proteins by the fractionation procedure leading up to and including the glycerol gradient velocity sedimentation step.

Protein concentrations were determined by the dye-binding method of Bradford (5), using dye-containing reagent purchased from Bio-Rad Laboratories and bovine serum albumin as the standard. The following size standards were used to calibrate the Sephacryl S-300 sizing column: thyroglobulin, $670 \mathrm{kDa}$; gamma globulin, $158 \mathrm{kDa}$; ovalbumin, 44 $\mathrm{kDa}$; myoglobin (Bio-Rad Laboratories), $17 \mathrm{kDa}$, and $E$. coli $\beta$-galactosidase (Sigma), $540 \mathrm{kDa}$.

Yeast polysome preparation and gradient analysis. Yeast extracts were prepared as described by Warner et al. (50), with minor modifications. Yeast cultures $(300 \mathrm{ml})$ in YEPD medium were grown at $23^{\circ} \mathrm{C}$ to an $\mathrm{OD}_{600}$ of 1.0 . One half of the cell culture was collected by filtration $(0.2-\mu \mathrm{m}$-pore-size filter; Costar), resuspended in $25 \mathrm{ml}$ of YEPD, added to 150 $\mathrm{ml}$ of YEPD prewarmed to $37^{\circ} \mathrm{C}$, and then incubated for 15 min in a $37^{\circ} \mathrm{C}$ water bath shaker; the remaining half of the culture was maintained at $23^{\circ} \mathrm{C}$. Cycloheximide was added to the cultures to a final concentration of $50 \mu \mathrm{g} / \mathrm{ml}$, and the cultures were placed immediately into ice water. Cells were harvested by centrifugation at $3,600 \times g$ for $5 \mathrm{~min}$, washed with $10 \mathrm{ml}$ of ice-cold breaking buffer $(10 \mathrm{mM}$ Tris- $\mathrm{HCl}[\mathrm{pH}$ 7.4], $100 \mathrm{mM} \mathrm{NaCl}, 30 \mathrm{mM} \mathrm{MgCl}, 50 \mu \mathrm{g}$ of cycloheximide per $\mathrm{ml}, 200 \mu \mathrm{g}$ of heparin per $\mathrm{ml}, 0.2 \mu \mathrm{l}$ of diethyl pyrocarbonate per $\mathrm{ml}$ ), and resuspended in $1 \mathrm{ml}$ of breaking buffer. Glass beads (0.44-mm diameter) were added (to approximately one-fourth of the final volume), and cells were vortexed eight times for $15 \mathrm{~s}$ each time with 15 -s intervals on ice. One milliliter of lysis buffer was added, and the extract was cleared by two sequential centrifugations steps $(5,000 \times$ $g$ for $5 \mathrm{~min}$ and $12,000 \times g$ for $10 \mathrm{~min})$. Twenty five $\mathrm{OD}_{260}$ units of the supernatant $(300$ to $600 \mu \mathrm{l})$ was layered on 12-ml linear 7 to $47 \%$ or 15 to $35 \%$ sucrose gradients equilibrated with $50 \mathrm{mM}$ Tris-acetate $(\mathrm{pH} 7.6), 50 \mathrm{mM} \mathrm{NH}_{4} \mathrm{Cl}, 12 \mathrm{mM}$ $\mathrm{MgCl}_{2}$, and $1 \mathrm{mM}$ dithiothreitol and centrifuged at $4^{\circ} \mathrm{C}$ in an $\mathrm{SW} 41$ rotor at $39,000 \mathrm{rpm}$ for 2 or $4.5 \mathrm{~h}$, respectively. The gradients were fractionated in an ISCO gradient collector, scanning at $254 \mathrm{~nm}$ and collecting 0.6-ml fractions. Proteins were precipitated by the addition of $200 \mu \mathrm{l}$ of $50 \%$ TCA and frozen overnight at $-20^{\circ} \mathrm{C}$. Precipitated proteins were pelleted in a microfuge for $15 \mathrm{~min}$, washed twice with ice-cold acetone, dried under vacuum, and resuspended in $100 \mu \mathrm{l}$ of Laemmli sample buffer. Fifty microliters of each fraction was electrophoresed on $10 \%$ SDS-polyacrylamide gels and analyzed by immunoblotting.

Polysomal RNA distributions on 7 to $47 \%$ sucrose gradients were determined by RNA blot hybridization analysis. Total RNA from the sucrose gradient fractions prepared as described above was precipitated overnight at $-20^{\circ} \mathrm{C}$ by the addition of $1.2 \mathrm{ml}$ of cold ethanol. Precipitated RNA was pelleted by centrifugation at $9,500 \times g$ for $20 \mathrm{~min}$ in an HS4 rotor (Sorvall) at $0^{\circ} \mathrm{C}$. RNA was resuspended in $300 \mu \mathrm{l}$ of RNA lysis buffer ( $20 \mathrm{mM}$ Tris- $\mathrm{HCl}$ [pH 7.4], $100 \mathrm{mM} \mathrm{NaCl}$, $2.5 \mathrm{mM}$ EDTA, 1\% SDS) and extracted three times with phenol equilibrated in RNA lysis buffer lacking SDS. The RNA was precipitated by the addition of $600 \mu$ l of cold ethanol and pelleted by centrifugation at 9,500 $\times g$ for 20 min. RNA pellets were resuspended in $100 \mu \mathrm{l}$ of $\mathrm{H}_{2} \mathrm{O}$, lyophilized, and resuspended in $10 \mu \mathrm{l}$ of $\mathrm{H}_{2} \mathrm{O}$. Five microliters of each sample was electrophoresed through a $1.2 \%$ formaldehyde-agarose gel, transferred to GeneScreen Plus (Dupont), and probed for pyruvate kinase ( $P Y K I)$ mRNA by hybridization, all as previously described (25). Plasmid pFR2, which contains the $P Y K 1$ gene on a $6.7-\mathrm{kb}$ HindIII DNA fragment (6), was radiolabeled with $\left[\alpha-{ }^{32} \mathrm{P}\right] \mathrm{dCTP}$ by the random primer method (13) and served as the probe.

\section{RESULTS}

Biochemical cofractionation of a protein complex containing GCD1, GCD2, and GCN3 with the translation initiation factor subunits eIF-2 $\alpha$ and eIF-2 $\beta$. Previous genetic analysis revealed that certain mutations affecting the $\alpha$ and $\beta$ subunits of eIF-2 have a $\mathrm{Gcd}^{-}$phenotype, causing constitutive derepression of GCN4 translation (52). In addition, like certain gcd mutations, the sui2-1 mutation is lethal in a $g c n 3$ deletion strain. These results suggested a functional connection between GCD factors and the subunits of eIF-2. For this reason, we set out to determine whether the GCD1, GCD2, and GCN3 proteins are physically associated with yeast eIF-2. In parallel, we looked for an association between the GCD factors and PRT1, a protein shown to be required for translation initiation and thought to be a subunit of the eukaryotic translation initiation factor 3 (eIF-3) of $S$. cerevisiae $(14,23,34)$. In higher eukaryotes, eIF-3 is a highmolecular-weight complex containing 7 to 10 polypeptides that functions to promote association of a ternary complex composed of eIF-2, GTP, and Met-tRNA ${ }_{i}^{\text {Met }}$ with the 40S ribosomal subunit $(33,40)$. Given the close functional association between eIF-3 and eIF-2, we imagined that GCD1, GCD2, or GCN3 could be subunits of the eIF-3 complex.

Using specific antisera to detect each of these proteins (see Materials and Methods and Fig. 1), we compared the fractionation of GCD1, GCD2, and GCN3 with PRT1 and the $\alpha$ and $\beta$ subunits of eIF- 2 during a partial purification of translation initiation factors from yeast cells (12). Greater than $80 \%$ of the GCD1, GCD2, and GCN3 polypeptides were found in a high-salt wash of yeast ribosomes that had been pelleted by centrifugation; this RSW fraction also contained the majority of PRT1 and about $75 \%$ of eIF- $2 \alpha$ and eIF-2 $\beta$ (data not shown). The RSW was then fractionated according to size, using Sephacryl S-300 gel filtration chromatography. Figure $2 \mathrm{~A}$ shows a typical absorbance profile of this fractionation for molecular weights in excess of about 70,000 . Total proteins in each fraction were analyzed by SDSpolyacrylamide gel electrophoresis (PAGE) and immunoblotting, using the antisera described in Materials and Methods. As shown in Fig. 2B, the GCD1, GCD2, and GCN3 proteins present in the RSW eluted from the Sephacryl S-300 column in a nearly identical fashion at a position corresponding to an $M_{\mathrm{r}}$ value of approximately 600,000 . None of these proteins was found in the later fractions from the column expected to contain their monomeric forms with molecular weights of $65,700,70,800$, and 34,000 , respectively, for GCD1, GCD2, and GCN3 (data not shown). Thus, most of the GCD1, GCD2, and GCN3 present in the RSW appears to exist as a high-molecular-weight complex. As shown below, the same conclusion was reached when whole-cell extracts were fractionated by velocity sedimentation on sucrose gradients. The PRT1 protein eluted from the S-300 column at a position that corresponds to an apparent $M_{\mathrm{r}}$ of 500,000 , similar to that reported for eIF-3 from higher eukaryotes (33). The fact that GCD1, GCD2, and GCN3 exhibit an elution profile different from that of PRT1 suggests that these three proteins and PRT1 exist in different high-molecularweight complexes.

Typically, $80 \%$ of the eIF- $2 \alpha$ and eIF- $2 \beta$ in the RSW fraction eluted from Sephacryl S-300 with an apparent $M_{\mathrm{r}}$ 


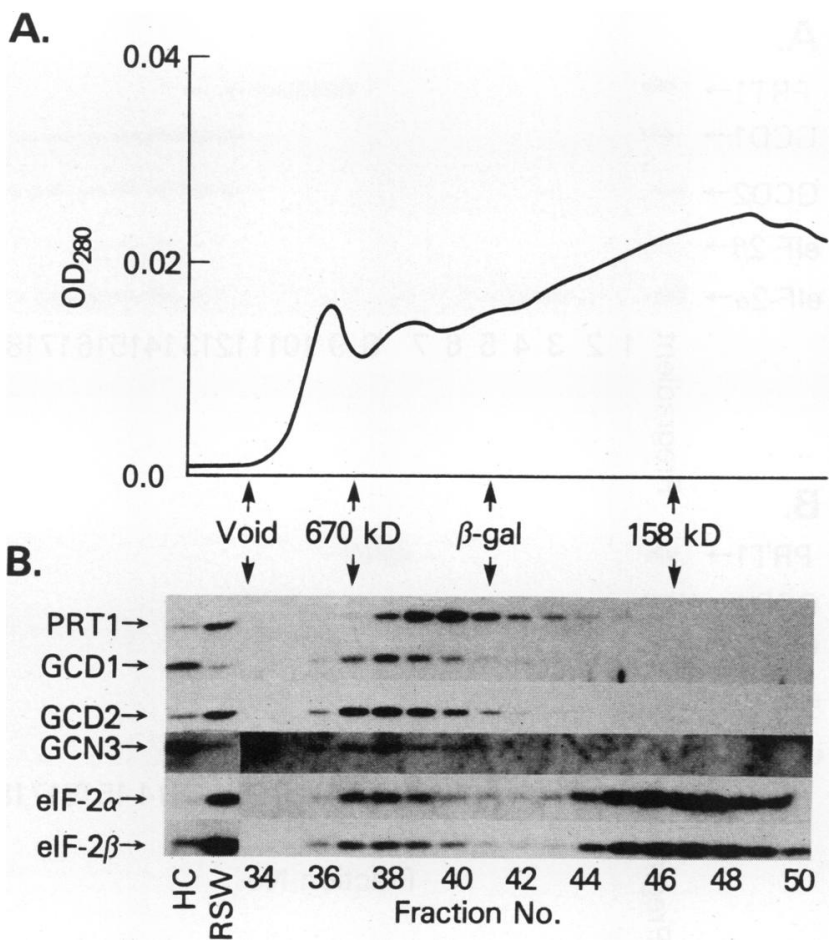

FIG. 2. Immunoblot analysis of the RSW fractionated by Sephacryl S-300 gel filtration chromatography. The RSW from wild-type strain TD28, prepared as described in Materials and Methods, was size fractionated on a Sephacryl S-300 gel filtration column, and 1-ml fractions were collected. $E$. coli $\beta$-galactosidase ( $\beta$-gal; $3 \mu \mathrm{g}$ ) added to the RSW served as an internal size standard; its elution position was determined by assaying fractions $(10 \mu \mathrm{l})$ for enzyme activity as described previously (7). The $\beta$-galactosidase activity elutes from the column with an apparent $M_{\mathrm{r}}$ value of 420,000. A 50- $\mu$ l sample of each fraction was subjected to $10 \%$ SDS-PAGE and analyzed by immunoblotting, using the antibodies and dilutions described in the legend to Fig. 1, as well as antibodies against yeast eIF-2 $\alpha$ (1:500 dilution) and eIF-2 $\beta$ (1:300 dilution). (A) UV absorbance profile of 5 mg of RSW fractionated on the Sephacryl S-300 column. Elution positions of molecular weight standards are indicated. (B) Fractions from the separation shown in panel $A$ analyzed by immunoblotting. The panel represent composites of identical gels that were blotted and probed separately with different antibodies. Immunoreactive polypeptides detected by their corresponding antisera are indicated at the left. Lane HC, $50 \mu \mathrm{g}$ of extracts from transformants containing the following genes on high-copy-number plasmids: GCD1 (EY412), GCD2 (H1388), and GCN3 (EY243). Lane RSW, $50 \mu \mathrm{g}$ of the total RSW loaded on the column.

value of 145,000 to 170,000 (peak fractions 43 to 48 ; Fig. 2B), in agreement with the molecular weight of 140,000 estimated for the yeast eIF- $2 \alpha \cdot \beta \cdot \gamma$ complex based on its biochemical activity in ternary complex formation (2). Interestingly, most of the remainder of eIF- $2 \alpha$ and eIF-2 $\beta$ eluted in the same fractions that contain GCD1, GCD2, and GCN3 (fractions 36 to 39; Fig. 2B). Note that the stoichiometries of the $\alpha$ and $\beta$ subunits of eIF-2 were very similar in the $170,000-$ and $600,000-\mathrm{Da}$ fractions from the column. These results suggest that two pools of eIF-2 are present in the yeast RSW: a free pool that may represent the eIF- $2 \alpha \cdot \beta \cdot \gamma$ complex $\left(M_{\mathrm{r}}\right.$ of approximately 170,000$)$ and a high-molecular-weight pool $\left(M_{\mathrm{r}}\right.$ of approximately 600,000$)$ that cofractionates with GCD1, GCD2, and GCN3.

To address further whether GCD1, GCD2, and GCN3 are
A.

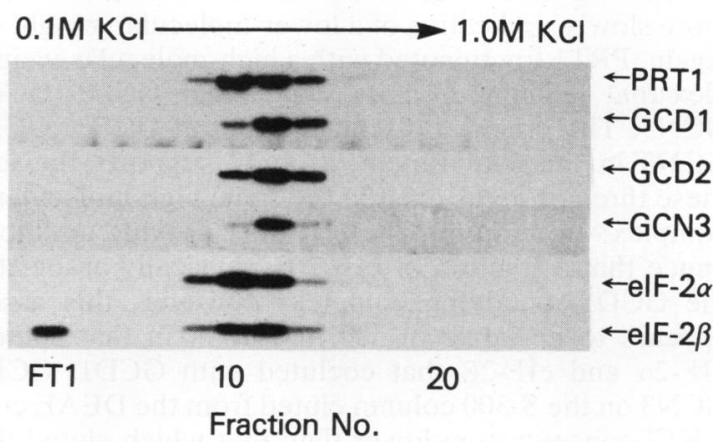

B.

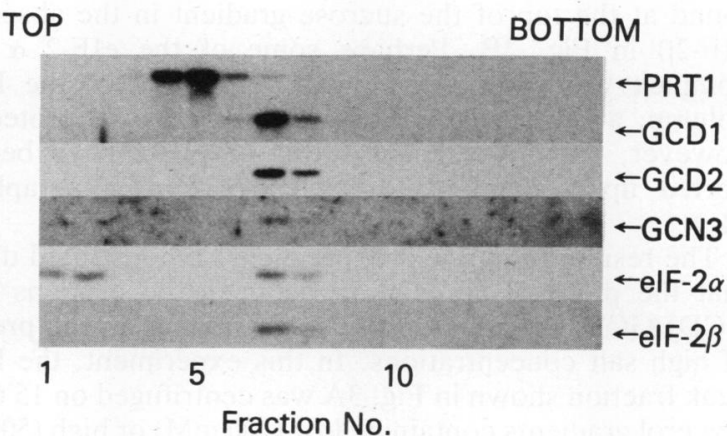

FIG. 3. Immunoblot analysis of DEAE ion-exchange chromatography and sucrose gradient velocity. sedimentation of the GCD1, GCD2, and GCN3 peak fractions from Sephacryl S-300. (A) Sephacryl S-300 fractions 36 to 39 (Fig. 2C) were pooled (1 mg of total protein) and applied to a DEAE $\mathrm{Cl}-6 \mathrm{~B}$ ion-exchange column. Proteins were eluted with $50 \mathrm{ml}$ of a linear salt gradient of 0.1 to 1.0 $\mathrm{M} \mathrm{KCl}$ in DEAE buffer, and 2-ml fractions were collected. A 100- $\mu$ l sample of each fraction was subjected to 10\% SDS-PAGE and analyzed by immunoblotting as described for Fig. 1 and 2. (B) Fractions 11 and 12 from the DEAE column were pooled, concentrated, and dialyzed against DEAE buffer $(0.1 \mathrm{M} \mathrm{KCl})$ in a Centricon-30. A $60-\mu \mathrm{g}$ sample of this material was centrifuged on 15 to $30 \%$ sucrose gradients for $27,500 \mathrm{rpm}$ at $4^{\circ} \mathrm{C}$ for $24 \mathrm{~h}$ in an SW41 rotor. In a parallel set of tubes, $E$. coli $\beta$-galactosidase (15S) sedimented to a position in the gradient that corresponds to fraction 7. Fractions of $600 \mu \mathrm{l}$ were collected and precipitated with $200 \mu$ l of $50 \%$ TCA, washed three times with cold acetone, vacuum dried, and resuspended in $200 \mu \mathrm{l}$ of Laemmli buffer. Samples of $50 \mu$ l were analyzed by immunoblotting as described above. Fractions 1 and 16 correspond to the top and bottom of the sucrose gradient, respectively.

present in the same high-molecular-weight complex and whether eIF-2 interacts with this complex, we subjected the peak fractions from the Sephacryl S-300 column containing GCD1, GCD2, and GCN3 (fractions 36 to 39; Fig. 2) and analyzed as described above by immunoblotting. GCD1, GCD2, and GCN3 coeluted from DEAE at approximately 300 to $400 \mathrm{mM} \mathrm{KCl}$ (Fig. 3A). The $\alpha$ and $\beta$ subunits of eIF-2 and PRT1 were enriched in these same fractions from the DEAE column; however, a portion of these proteins eluted at a slightly lower $\mathrm{KCl}$ concentration than did the peak fraction containing GCD1, GCD2, and GCN3. When the peak fraction from the DEAE column containing GCD1, GCD2, and GCN3 was centrifuged on 15 to $30 \%$ sucrose gradients, all of these proteins and the eIF-2 $\beta$ present in the sample comigrated with a sedimentation coefficient of approximately $15 \mathrm{~S}$ (Fig. 3B). A portion of eIF-2 $\alpha$ also comi- 
grated with these proteins, whereas the remainder migrated more slowly, indicative of a lower-molecular-weight species. Again, PRT1 fractionated with a high-molecular-weight complex that sedimented more slowly than GCD1, GCD2, and GCN3. The precise cosedimentation of GCD1, GCD2, and GCN3 in this experiment strongly supports the idea that these three proteins exist in the same high-molecular-weight complex. In addition, these results provide additional evidence that a fraction of eIF-2 is physically associated with the GCD1-containing complex; however, this association appears to be labile in $300 \mathrm{mM} \mathrm{KCl}$, in that some of the eIF- $2 \alpha$ and eIF-2 $\beta$ that coeluted with GCD1, GCD2, and GCN3 on the S-300 column eluted from the DEAE column at a $\mathrm{KCl}$ concentration lower than that which eluted the GCD proteins (Fig. 3A). It is not understood why eIF-2 $\alpha$ was found at the top of the sucrose gradient in the absence of eIF-2 $\beta$ in Fig. 3B. Perhaps some of the eIF-2 $\alpha \cdot \beta \cdot \gamma$ complex was dissociated during elution from the DEAE column, and free eIF- $2 \beta$ may be sensitive to proteolysis; however, subunit-deficient forms of eIF-2 have been reported upon standard ion-exchange chromatography (3, 41a).

The results of the next experiment demonstrated directly that the physical association between the proteins in the GCD1/GCD2/GCN3 complex is maintained in the presence of high salt concentrations. In this experiment, the DEAE peak fraction shown in Fig. 3A was centrifuged on 15 to $40 \%$ glycerol gradients containing low $(100 \mathrm{mM})$ or high $(500 \mathrm{mM})$ concentrations of $\mathrm{KCl}$. As in Fig. 3B, GCD1 and GCD2 cosedimented exactly in the low-salt glycerol gradient (Fig. 4A). (In this experiment, there may have been some aggregation of these proteins, producing species that migrated more rapidly than $15 S$ ). Again, a fraction of eIF- $2 \alpha$ and eIF-2 $\beta$ comigrated with GCD1 and GCD2, although the more slowly sedimenting species of the GCD1-containing complex appeared to be depleted of both eIF-2 subunits. In the glycerol gradient containing $500 \mathrm{mM} \mathrm{KCl}$ (Fig. 4B), GCD1 and GCD2 again comigrated precisely; however, all of the $\alpha$ and $\beta$ subunits of eIF-2 were detected exclusively near the top the gradient at a position consistent with the sedimentation rate of the free form of the eIF-2 complex (fractions 3 and 4). GCN3 comigrated with GCD1 and GCD2 in both the low-salt and high-salt gradients (data not shown). These results provide strong support for the idea that GCD1, GCD2, and GCN3 are integral components of the same high-molecular-weight complex. We suggest that this complex is loosely associated with a portion of the eIF-2 complex and that this interaction is disrupted by high concentrations of $\mathrm{KCl}$. As suggested above, some dissociation of eIF-2 from the GCD1/GCD2/GCN3 complex probably occurred during elution of these proteins from the DEAE column, as fractions 11 to 13 of the low-salt gradient in Fig. 4A contained GCD1/GCD2/GCN3 complexes devoid of eIF-2. As would be expected, the latter complexes migrated more slowly than those present in fractions 14 to 18 containing both the GCD1/GCD2/GCN3 complex and the subunits of eIF-2.

Coimmunoprecipitation of GCD1, GCD2, GCN3, and the $\alpha$ and $\beta$ subunits of eIF-2. To demonstrate by a different approach that GCD1, GCD2, and GCN3 are components of the same complex, we used antibodies specific for GCD1 in an attempt to coimmunoprecipitate all three proteins from the RSW fraction under nondenaturing conditions. Both the pellet (containing the immune complexes) and the supernatant fractions were subjected to SDS-PAGE and immunoblot analysis using the various antisera described above. As

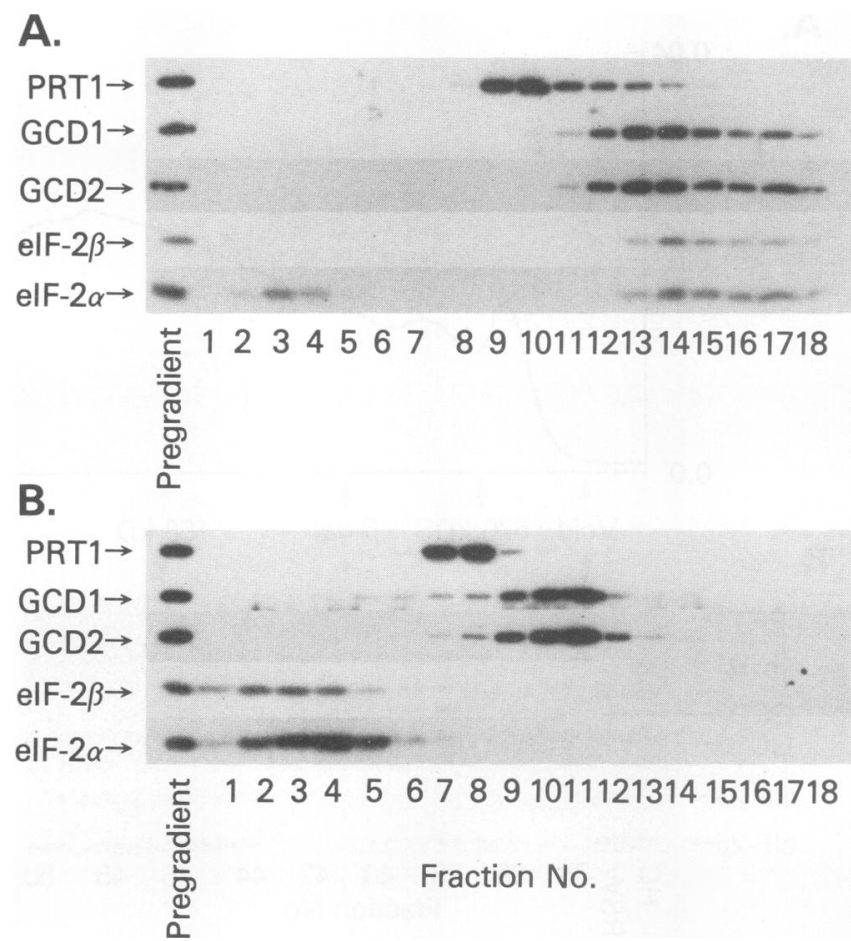

FIG. 4. Immunoblot analysis of low- and high-salt glycerol gradient velocity sedimentation. Samples $(500 \mu \mathrm{g})$ of pooled DEAE fractions 11 and 12 (Fig. 3A), concentrated and dialyzed against 100 mM DEAE buffer, were centrifuged on 15 to $40 \%$ glycerol gradients containing 100 (A) or 500 (B) $\mathrm{mM} \mathrm{KCl}$. Gradients were centrifuged at $39,000 \mathrm{rpm}$ for $25 \mathrm{~h}$ at $4^{\circ} \mathrm{C}$ in an SW41 rotor. In a parallel set of tubes, $E$. coli $\beta$-galactosidase (15S) sedimented to a position in the low-salt gradients that corresponds to fractions 11 and 12 . Gradients were fractionated while $600-\mu$ l fractions were collected; $30 \mu \mathrm{l}$ of each fraction was subjected to $10 \%$ SDS-PAGE and analyzed by immunoblotting as described for Fig. 1 and 2.

shown in Fig. 5A, the pellet fraction obtained by using GCD1 antiserum contained greater than $80 \%$ of the GCD1, GCD2, and GCN3, but none of the PRT1, that was present in the RSW fraction. Comparison of stained proteins in the pellet and supernatant fractions following SDS-PAGE suggested that only a few percent of the total proteins in the RSW was present in the pellet fraction containing most of the GCD1, GCD2, and GCN3. Antibodies specific for GCD2 immunoprecipitated similar amounts of GCD1, GCD2, and GCN3 from the RSW (data not shown). By contrast, none of these proteins was present in the pellet fractions obtained by using either preimmune serum or serum specific for PRT1 (Fig. 5A and $B$ ). These observations provide strong support for our conclusion that GCD1, GCD2, and GCN3 are present in the same protein complex.

In addition to GCD1, GCD2, and GCN3, about $25 \%$ of the eIF- $2 \alpha$ and eIF- $2 \beta$ subunits in the RSW were present in the pellet fraction obtained by using GCD1 antiserum, whereas none of the eIF- $2 \alpha$ and only a small amount of eIF- $2 \beta$ was found in the pellet fraction obtained by using preimmune serum (Fig. 5A). The proportions of eIF-2 $\alpha$ and eIF-2 $\beta$ that were immunoprecipitated by GCD1 antiserum are similar to the percentages of these subunits that coeluted with GCD1, GCD2, and GCN3 in the high-molecular-weight region of the Sephacryl S-300 column (Fig. 2B). Similar amounts of the eIF-2 subunits were coimmunoprecipitated with the use of 


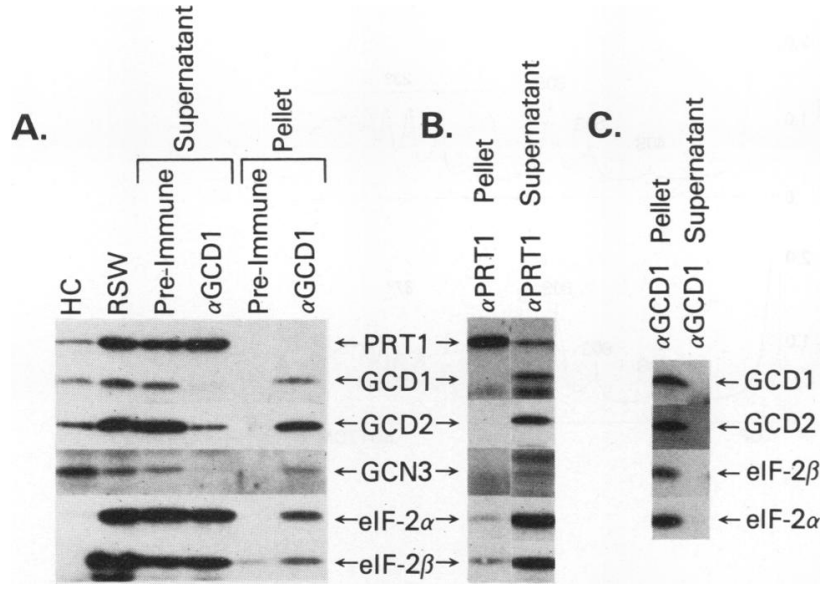

FIG. 5. Coimmunoprecipitation of GCD1, GCD2, GCN3, eIF- $2 \alpha$ and eIF-2 $\beta$ by antibodies against GCD1. The immunoglobulin $G$ fractions from $30 \mu \mathrm{l}$ of various sera were prebound to protein A-agarose beads for 1 to $2 \mathrm{~h}$ at room temperature in nondenaturing binding buffer as described in Materials and Methods. Protein fractions from wild-type strain TD28 were added to the beads, brought to a total volume of $200 \mu \mathrm{l}$ with binding buffer, and incubated for 2 to $3 \mathrm{~h}$ at $4^{\circ} \mathrm{C}$. Beads were pelleted, washed, and resuspended in $200 \mu \mathrm{l}$ of Laemmli buffer. The proteins in the supernatant fraction of the immunoprecipitation reactions were precipitated with $50 \%$ TCA, pelleted, dried, and resuspended in 200 $\mu l$ of Laemmli buffer; $66 \mu \mathrm{l}$ of the supernatant and pellet fractions was boiled for $2 \mathrm{~min}$, subjected to $10 \%$ SDS-PAGE, and analyzed by immunoblotting. (A) RSW $(200 \mu \mathrm{g})$ immunoprecipitated with GCD1preimmune or GCD1-specific ( $\alpha \mathrm{GCD} 1)$ antibodies; (B) RSW (200 $\mu \mathrm{g})$ immunoprecipitated with PRT1-specific antibodies ( $\alpha$ PRT1); (C) pooled fractions 13 and $14(2.5 \mu \mathrm{g})$ from the low-salt glycerol gradient shown in Fig. 4A immunoprecipitated with GCD1-specific antibodies. Lane $\mathrm{HC}, 50 \mu \mathrm{g}$ of extracts from the transformants containing high-copy-number $G C D 1, G C D 2$, or $G C N 3$, described in the legend to Fig. 1; lane RSW, $66 \mu \mathrm{g}$ of RSW from yeast strain TD28.

GCD2-specific antiserum (data not shown). However, small amounts of the eIF-2 subunits were also immunoprecipitated by PRT1 antiserum (Fig. 5B), raising the possibility that eIF- $2 \alpha$ and eIF-2 $\beta$ were immunoprecipitated by GCD1 antiserum as the result of a nonspecific association of these proteins with rabbit immunoglobulin G. In an effort to eliminate the latter possibility, we analyzed more highly purified fractions of GCD1, GCD2, and GCN3 that also contained eIF- $2 \alpha$ and eIF-2 $\beta$. Incubation of the Sephacryl S-300 or the DEAE peak fractions containing GCD1, GCD2, and GCN3 with antibodies against GCD1 resulted in coimmunoprecipitation of 50 to $80 \%$ of the eIF- $2 \alpha$ and $-\beta$ with all of the GCD1, GCD2, and GCN3 present in these fractions. In contrast, eIF- $2 \alpha$ and $-\beta$ were not observed in the pellet fraction when either preimmune serum or PRT1 antibodies were used for immunoprecipitations of the same fractions (data not shown). Furthermore, as shown in Fig. 5C, incubation of the low-salt glycerol gradient peak fraction containing GCD1, GCD2, GCN3 and the high-molecular-weight form of the eIF-2 subunits (fractions 13 and 14 in Fig. 4A) with GCD1 antiserum resulted in coimmunoprecipitation of greater than $90 \%$ of the eIF- $2 \alpha$ and eIF- $2 \beta$ with all of the GCD1 and GCD2 present in these fractions. Thus, partial purification of the high-molecular-weight complex containing GCD1, GCD2, and GCN3 greatly increased the percentage of copurifying eIF- $2 \alpha$ and eIF- $2 \beta$ that was immunopre- cipitated with antibodies against GCD1. The results in Fig. 5C strongly suggest that the high-molecular-weight fractions of eIF- $2 \alpha$ and eIF- $2 \beta$ are specifically associated with the $600,000-D a$ protein complex containing GCD1, GCD2, and GCN3.

Translation initiation is defective in a gcd1-101 mutant. The involvement of GCD1, GCD2, and GCN3 in translational control of GCN4, the fact that GCD1 and GCD2 have essential functions in addition to their roles in general amino acid control, and the results described above suggesting a specific association of these factors with eIF-2 all suggest that GCD1 and GCD2 are general translation initiation factors. To test this possibility further, we investigated the effects of the gcdl-101 mutation on total polysome profiles. This mutation impairs growth in rich medium at $37^{\circ} \mathrm{C}$. Isogenic gcd1-101 mutant and wild-type cells were grown in rich medium at $23^{\circ} \mathrm{C}$ and shifted to $37^{\circ} \mathrm{C}$ for $15 \mathrm{~min}$, after which cycloheximide was added to prevent further translation elongation. Cell extracts prepared from these cultures were fractionated by centrifugation on 7 to $47 \%$ sucrose gradients to separate $80 \mathrm{~S}$ ribosomes from polysomes. In the gcdl-101 mutant, we observed a significant increase in the monosome/polysome ratio, from 0.3 to 3.0 , after only $15 \mathrm{~min}$ at $37^{\circ} \mathrm{C}$ (Fig. 6A). By contrast, the monosome/polysome ratio in the wild-type strain increased only slightly, from $\mathbf{0 . 3}$ to 0.5 (Fig. 6B). After $60 \mathrm{~min}$ at $37^{\circ} \mathrm{C}$, the monosome/ polysome ratio was restored to 0.3 in the wild-type strain but remained at 3.0 in the gcdl-101 mutant.

A similar increase in the monosome/polysome ratio was observed when a yeast strain containing the sui2-1 allele, a temperature-sensitive mutation in the structural gene for eIF-2 $\alpha$, was incubated at $37^{\circ} \mathrm{C}$ (Fig. 6C). This phenomenon has also been described for a mutation (prtl-1) in the gene encoding the PRT1 protein (23). The reduction in polysome content in these mutants at the restrictive temperature is thought to arise from a specific defect in translation initiation: continued translation elongation at $37^{\circ} \mathrm{C}$ leads to runoff of polysomes and accumulation of inactive $80 \mathrm{~S}$ couples consisting of $40 \mathrm{~S}$ and $60 \mathrm{~S}$ subunits joined in the absence of mRNA (23). This is in contrast to temperature-sensitive yeast strains defective in translation elongation that do not accumulate $80 \mathrm{~S}$ couples at the restrictive temperature $(23$, 34). The bottom panel in Fig. 6A shows that the monosome/ polysome ratio was unchanged when cycloheximide was added to the $\operatorname{gcdl}-101$ strain before shifting to the nonpermissive temperature. This result confirms that translation elongation occurs in the $g c d 1-101$ mutant at the restrictive temperature and supports the view that diminution of polysomes under these conditions results primarily from reduced initiation of new polypeptide chains. Presumably, $80 \mathrm{~S}$ couples arise at $37^{\circ} \mathrm{C}$ in these mutants because the free ribosomal subunit concentrations exceed those of initiation factors (eIF-3 and eIF-6) that prevent subunit association in preparation for the initiation process (33). Unlike translating $80 \mathrm{~S}$ ribosomes, $80 \mathrm{~S}$ couples can be dissociated in $0.5 \mathrm{M} \mathrm{KCl}$ $(14 \mathrm{a}, 31)$.

A second indication of a reduced rate of translation initiation in the gcdl-101 mutant is that the total polysome size distribution shifts to smaller species after $15 \mathrm{~min}$ at $37^{\circ} \mathrm{C}$ (Fig. 6A). For example, in the gcdl-101 mutant, the 2-mer and 3-mer polysomes increased from 21 to $31 \%$ of the total polysomes following the shift to $37^{\circ} \mathrm{C}$, whereas the proportion of these small polysomes decreased slightly, from 21 to $16 \%$, in the wild-type strain following the temperature shift. In addition, RNA blot hybridization analysis of the $P Y K I$ mRNA distribution in the polysomal fractions indicated that 
A
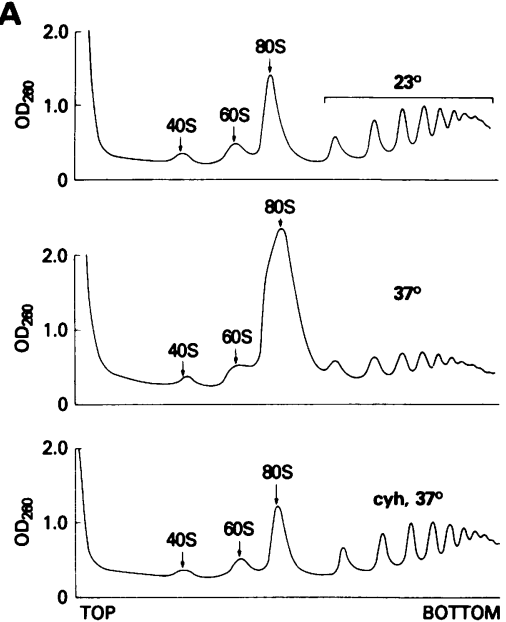

C
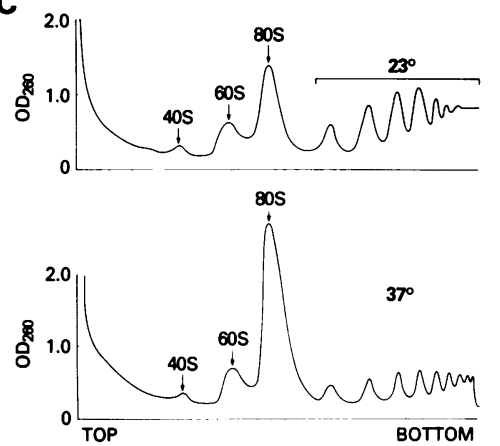

B
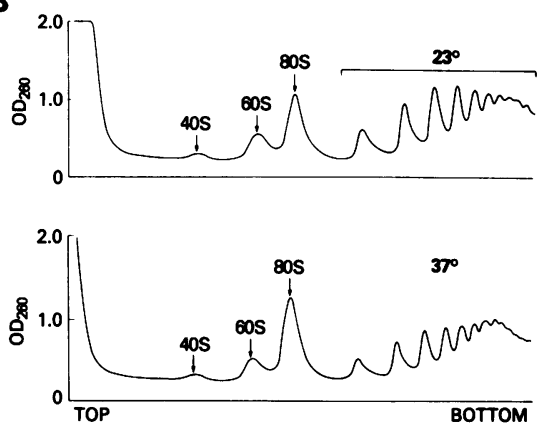

D
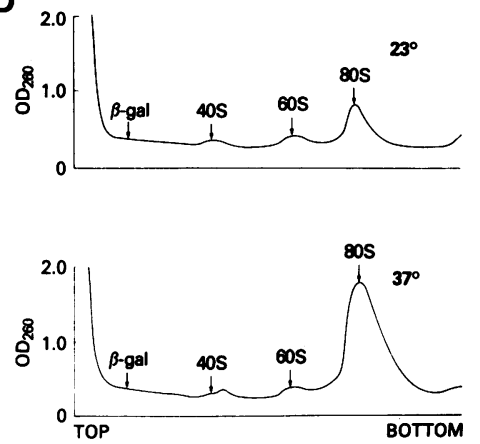

FIG. 6. Polysome profile analysis of mutant and wild-type yeast strains grown at permissive and nonpermissive temperatures. Extracts prepared from wild-type and mutant strains grown in YEPD medium at different temperatures were centrifuged on 7 to $47 \%$ sucrose gradients at $4^{\circ} \mathrm{C}$ for $2.5 \mathrm{~h}$ at $39,000 \mathrm{rpm}$ in an SW41 rotor. Gradients were fractionated from the top in an ISCO gradient collector while scanning at 254 $\mathrm{nm}$. (A) Polysome profiles of the temperature-sensitive gcdl-101 mutant $\mathrm{F} 98$ grown continuously at $23^{\circ} \mathrm{C}$ or after shifting from 23 to $37^{\circ} \mathrm{C}$ for $15 \mathrm{~min}$. Cyh, $37^{\circ}$, cycloheximide was added to the culture just before shifting to $37^{\circ} \mathrm{C}$. (B) Isogenic wild-type $G C D 1$ strain MC1001 grown under the same conditions as strain F98 in panel A. (C) Temperature-sensitive sui2-1 mutant strain 117-8AR20 containing a mutation affecting the $\alpha$ subunit of yeast eIF-2 grown under the conditions described for panels A and B. (D) Polysome profile of the temperature-sensitive gcdl-101 mutant $\mathrm{F} 98$ grown at $23^{\circ} \mathrm{C}$ or after shifting from 23 to $37^{\circ} \mathrm{C}$ for $15 \mathrm{~min}$. Extracts were centrifuged on 15 to $35 \%$ gradients for $4 \mathrm{~h}$ at $39,000 \mathrm{rpm}$ in an SW41 rotor.

the average size of polysomes containing this transcript decreased when the gcdl-101 mutant was shifted from 23 to $37^{\circ} \mathrm{C}$, whereas no such reduction occurred when the wildtype strain was grown at $37^{\circ} \mathrm{C}$ (Fig. 7). All of the $P Y K 1$ mRNA bound to polysomes in the gcdl-101 mutant appeared to be full length; thus, the smaller average size of $P Y K I$ specific polysomes cannot be attributed to shortening of the transcript. However, the yield of total $P Y K I$ mRNA was lower in the mutant than in the wild type, and this difference was exacerbated by incubation at $37^{\circ} \mathrm{C}$. We presume that the reduced number of ribosomes associated with $P Y K 1 \mathrm{mRNA}$ in the mutant leads to increased degradation of the transcript. This may explain the rather modest reduction in the average size of the polysomes seen in the gcdl-101 mutant following the shift to $37^{\circ} \mathrm{C}$, in the following way: with lower mRNA levels, there would be less competition for initiation factors, partially offsetting the reduced efficiency of initiation associated with the gcdl-101 mutation for those mRNA molecules that remain intact.

The gcd1-101 mutant accumulates translation initiation intermediates at the restrictive temperature. In addition to the

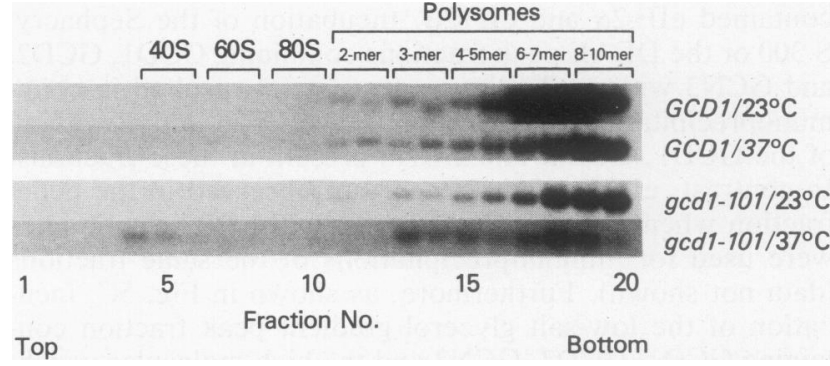

FIG. 7. RNA blot hybridization analysis of the distribution of PYKI mRNA in polysomes from cell extracts from wild-type and mutant $g c d l-101$ strains. Total RNA was isolated from the sucrose gradient fractions described in the legend to Fig. 6, and equal volumes of each fraction were electrophoresed on $1.2 \%$ formaldehyde-agarose gels, transferred to GeneScreen Plus, and probed for pyruvate kinase $(P Y K 1)$ mRNA. 40 S and 60 S ribosomal subunits, $80 \mathrm{~S}$ monosomes, and polysome positions are indicated at the top. 


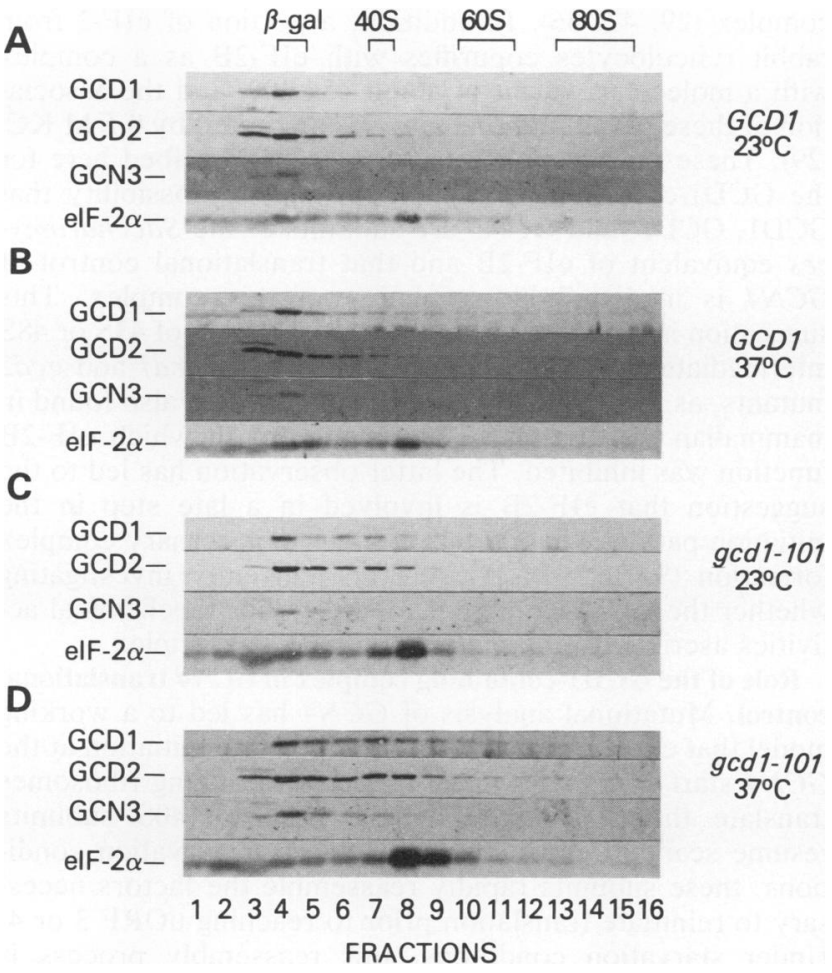

FIG. 8. Immunoblot analysis of GCD1, GCD2, GCN3, and eIF- $2 \alpha$ in sucrose gradient fractions of wild-type and mutant gcdl101 strains. Extracts from isogenic wild-type (MC1001) and gcdl101 mutant (F98) strains grown continuously at $23^{\circ} \mathrm{C}$ or after shifting to $37^{\circ} \mathrm{C}$ for $15 \mathrm{~min}$ were centrifuged on 15 to $35 \%$ sucrose gradients at $4^{\circ} \mathrm{C}$ for $4.5 \mathrm{~h}$ at $39,000 \mathrm{rpm}$. Gradients were fractionated from the top while $600-\mu \mathrm{l}$ fractions were collected. Protein samples from an equal volume of each fraction were subjected to $10 \%$ SDS-PAGE and analyzed by immunoblotting as described for Fig. 1 and 2 . Fractions 1 and 16 correspond to the top and bottom of the gradient, respectively. $E$. coli $\beta$-galactosidase $(1 \mu \mathrm{g})$ was added to the extracts prior to centrifugation and served as an internal molecular weight standard, migrating with a sedimentation coefficient of $15 \mathrm{~S}$. Positions of free $40 \mathrm{~S}$ and $60 \mathrm{~S}$ ribosomal subunits and $80 \mathrm{~S}$ monosomes are indicated.

decrease in polysome size and content seen in the gcdl-101 mutant at $37^{\circ} \mathrm{C}$, we generally observed a small but reproducible increase in the sedimentation rate of the $40 \mathrm{~S}$ subunits after the temperature shift (Fig. 6D). The latter observation raised the possibility that an initiation intermediate involving the 40 S subunit was accumulating in the $g c d l-101$ mutant at the restrictive temperature. To investigate this possibility further, we conducted immunoblot analysis of fractions from sucrose gradients similar to those shown in Fig. 6A and B.

Probing with antibodies against eIF- $2 \alpha$ revealed that in wild-type cells, eIF-2 $\alpha$ was localized throughout the top of the gradient with one peak at about $15 \mathrm{~S}$ and another between $40 \mathrm{~S}$ and $50 \mathrm{~S}$ (Fig. 8A and B). The $15 \mathrm{~S}$ species coincided with the GCD1/GCD2/GCN3 complex, as shown by probing of the same fractions with antibodies against these three proteins (Fig. 8A and B). The 40S-50S peak probably represents $43 \mathrm{~S}$ or $48 \mathrm{~S}$ initiation intermediates consisting of the small ribosomal subunit, eIF-3, and the ternary complex eIF-2 - GTP - Met-tRNA ${ }_{i}^{\text {Met }}$ (48S complexes also contain mRNA and additional initiation factors; 33). Even at the permissive temperature, gcdl-101 cells exhibited a higher percentage of eIF- $2 \alpha$ in the $40 \mathrm{~S}-50 \mathrm{~S}$ region of the gradient than did the isogenic wild-type strain (Fig. 8C), and incubation of the $g c d 1-101$ mutant at $37^{\circ} \mathrm{C}$ for $15 \mathrm{~min}$ led to a dramatic increase in this fraction of eIF-2 $\alpha$ (Fig. 8D). The PRT1 protein showed a similar localization and also accumulated in the 40S-50S region when the gcdl-101 mutant was shifted to $37^{\circ} \mathrm{C}$ (data not shown), consistent with the suggestion that PRT1 is a subunit of eIF-3 (34). These results support the idea that $43 \mathrm{~S}$ or $48 \mathrm{~S}$ species accumulate in the gcdl-101 mutant under conditions in which translation initiation is impaired. This accumulation probably results from reduced utilization or increased formation of these reaction intermediates during the initiation process. Interestingly, we also observed an accumulation of GCD1, GCD2, and GCN3 in the $40 \mathrm{~S}-50 \mathrm{~S}$ regions of these gradients in the gcdl-101 mutant at $23^{\circ} \mathrm{C}$, and this accumulation was exacerbated by incubation at $37^{\circ} \mathrm{C}$. The association of these factors with the $40 \mathrm{~S}$ subunits was not dependent on the presence of cycloheximide during the preparation of the extracts (data not shown). Thus, the high-molecular-weight complex containing GCD1, GCD2, and GCN3 appears to physically interact with $43 \mathrm{~S}$ or $48 \mathrm{~S}$ translation initiation intermediates, suggesting that it plays a direct role in the initiation process.

\section{DISCUSSION}

GCD1, GCD2, and GCN3 are present in the same highmolecular-weight complex. The results of extensive genetic analysis suggested that the positive regulator GCN3 interacts closely with GCD1 and GCD2, two negative regulators of $G C N 4$ translation $(21,22,38)$. We have used a biochemical approach to investigate the nature of these interactions in order to better understand the role that these factors play in translational control. Biochemical fractionation studies demonstrated that GCD1, GCD2, and GCN3 were enriched in a high-salt wash of ribosomal pellets. These proteins cofractionated in Sephacryl S-300 gel filtration, DEAE ionexchange chromatography, and glycerol gradient centrifugation (Fig. 2 to 4), suggesting that they are components of the same high-molecular-weight complex with an $M_{\mathrm{r}}$ of 600,000 . This conclusion received strong support from the demonstration that GCD1, GCD2, and GCN3 could be coimmunoprecipitated by polyclonal antisera specific for GCD1 (Fig. 5) or GCD2. It was also supported by our finding that similar proportions of GCD1, GCD2, and GCN3 shifted their sedimentation rates in parallel from $15 \mathrm{~S}$ to $40 \mathrm{~S}-50 \mathrm{~S}$ when a gcdl-101 mutant was incubated at $37^{\circ} \mathrm{C}$ (Fig. 8). The latter is one of several observations suggesting that this protein complex has an essential role in translation initiation.

Two models were proposed previously to account for the fact that wild-type $G C N 3$ can suppress the phenotypes of certain $g c d l$ and $g c d 2$ mutations and that GCN3 and GCD2 exhibit amino acid sequence similarity (37). One model envisioned a protein complex in which GCN3 and GCD2 have subunit interactions with one another and with a third member of the complex mediated by their similar domains. It was proposed that GCN3 could overcome the phenotypes of the temperature-sensitive $g c d 2$ mutations by simply replacing the defective GCN3-like domain of GCD2 in the complex. Alternatively, GCN3 could stabilize the thermolabile gcd2-encoded protein by virtue of physical interaction between the two proteins in the complex. In wild-type cells under starvation conditions, modification of GCN3 would destabilize the whole complex, thereby reducing its function in translational repression of $G C N 4$. In the second model, GCD2 and GCN3 were envisioned as competing for the same 
substrate to carry out a reaction that is required for repression of GCN4, without any direct contact occurring between the two proteins. The data presented here clearly favor the first model involving a protein complex. Preliminary experiments have shown no obvious change in the association of GCD1, GCD2, and GCN3 in the high-molecular-weight complex in response to amino acid starvation of wild-type cells (6a). Therefore, it is more likely that the biochemical activity of the complex rather than its subunit composition is altered under starvation conditions.

GCD1 has an essential function in translation initiation. Several findings strongly suggest that GCD1, GCD2, and GCN3 have general functions in protein synthesis. The observation that a $g c d 1-101$ mutant shows reduced amounts of tRNA ${ }_{i}^{\text {Met }}$ bound to free $40 \mathrm{~S}$ subunits after incubation at $37^{\circ} \mathrm{C}$ (49), the isolation of mutations in SUI2 and SUI3 that phenotypically mimic $g c d l$ mutations for derepression of $G C N 4$, and the synthetic lethality of a sui2-1 gcn3s double mutation (52) all implicated GCD1, GCD2, and GCN3 in the translation initiation pathway at a step involving eIF-2. In agreement with this idea, we showed that a gcdl-10l strain exhibits a rapid reduction in the quantity and average size of polysomes, plus an accumulation of $80 \mathrm{~S}$ couples and $43 \mathrm{~S}$ or 48S translation initiation intermediates, following a shift to the restrictive temperature (Fig. 6 and 7). A similar runoff of polysomes has been observed in sui2-l (Fig. 6) and prtl-1 (23) temperature-sensitive mutants and is indicative of a defect in translation initiation associated with little or no effect on polypeptide chain elongation. Abnormalities in polysome profiles suggestive of initiation defects have also been observed in several mutants with lesions in GCD2, another protein in the GCD1-containing complex (14a). Incubation of $g c d 2-503$ cells at the restrictive temperature leads to increased amounts of eIF-2 associated with $40 \mathrm{~S}$ subunits, similar to the results shown for $g c d l-101$ cells in Fig. 8. In addition, gcd2-502 mutants exhibit halfmer polysomes indicative of an accumulation of $43 \mathrm{~S}$ preinitiation complexes bound to mRNA (14a). The apparent accumulation of $43 \mathrm{~S}$ or $48 \mathrm{~S}$ complexes in three different $g c d$ mutants suggests that utilization of preinitiation intermediates containing eIF-2 . GTP - Met-tRNA ${ }_{i}^{\text {Met }}$ ternary complexes is defective in these strains, rather than formation of ternary complexes. This suggestion is in accord with our findings that the GCD1/GCD/GCN3 complex is found in association with eIF-2 and that it also appears to interact with $43 \mathrm{~S}$ or $48 \mathrm{~S}$ preinitiation intermediates. The report that $g c d l-101$ cells have reduced amounts of ternary complexes bound to $40 \mathrm{~S}$ ribosomal subunits (43S or $48 \mathrm{~S}$ preinitiation complexes) when incubated at the restrictive temperature (48) may indicate that the GCD1-containing complex has multiple functions in the initiation pathway and that the length of time in which $g c d 1-101$ cells are incubated at $37^{\circ} \mathrm{C}$ determines whether early or late initiation intermediates accumulate when GCD1 function is impaired (see below).

There are interesting physical similarities between the GCD1-containing complex and the mammalian initiation factor eIF-2B, which recycles eIF-2 . GDP to eIF-2 - GTP after each round of initiation. Our results show that there are two pools of yeast eIF-2 in a ribosomal salt wash: the majority has a molecular weight roughly consistent with free eIF-2 $\alpha \cdot \beta \cdot \gamma$ complex; the second pool is of higher molecular weight and is found associated with the 15S GCD1/ GCD2/GCN3 complex. Similar distributions of free and high-molecular-weight pools of eIF-2 have been reported for mammalian cells (41), with the high-molecular-weight species found in association with the multisubunit 15S eIF-2B complex $(29,42,46)$. In addition, a portion of eIF-2 from rabbit reticulocytes copurifies with eIF-2B as a complex with a molecular weight of about 450,000 , and the association of these two initiation factors is disrupted by $0.5 \mathrm{M} \mathrm{KCl}$ (29). These are the same characteristics described here for the GCD1-containing complex, raising the possibility that GCD1, GCD2, and GCN3 are subunits of the Saccharomyces equivalent of eIF-2B and that translational control of GCN4 is mediated by regulation of this complex. This suggestion is consistent with the accumulation of $43 \mathrm{~S}$ or $48 \mathrm{~S}$ intermediates and halfmer polysomes in the $g c d l$ and $g c d 2$ mutants, as these initiation intermediates were also found in mammalian cell lysates under conditions in which eIF-2B function was inhibited. The latter observation has led to the suggestion that eIF-2B is involved in a late step in the initiation pathway in addition to its role in ternary complex formation $(9,15,17,45)$. We are currently investigating whether the GCD1-containing complex has biochemical activities ascribed to the mammalian eIF-2B complex.

Role of the GCD1-containing complex in GCN4 translational control. Mutational analysis of $G C N 4$ has led to a working model that explains how the uORFs regulate initiation at the GCN4 start codon (1). In this scheme, scanning ribosomes translate the 5'-proximal $\mathrm{UORF} 1$ and the $40 \mathrm{~S}$ subunits resume scanning downstream. Under nonstarvation conditions, these subunits rapidly reassemble the factors necessary to reinitiate translation prior to reaching uORF 3 or 4 . Under starvation conditions, this reassembly process is slower, enabling a significant fraction of $40 \mathrm{~S}$ subunits that have not reacquired these necessary factors to bypass uORFs 3 and 4 and to initiate farther downstream at GCN4 instead. The role of the positive factors GCN1, GCN2, and GCN3 is to retard the reassembly of complete initiation complexes by $40 \mathrm{~S}$ subunits scanning downstream from uORF1. Because this reinitiation process is less efficient than assembly of initiation complexes at the cap, a slight reduction in the activity of the GCD1-containing complex or of the levels of active eIF-2 would have a large effect on GCN4 translation but little effect on mRNAs lacking uORFs.

The accumulation of eIF- 2 in $43 \mathrm{~S}-48 \mathrm{~S}$ complexes in the gcd mutants suggests that a reduction in the rate of any one of several steps after the binding of eIF-2 . GTP . tRNA ${ }_{i}^{\text {Met }}$ ternary complexes to the $40 \mathrm{~S}$ subunit, including hydrolysis of GTP, dissociation of eIF-2 . GDP from the 40 S subunit, or joining of the $60 \mathrm{~S}$ subunit, could be responsible for the reduced efficiency of reinitiation at uORFs 3 and 4 that occurs in these mutants. Alternatively, sequestering eIF-2 in the initiation intermediates that accumulate in $g c d$ mutants could reduce the amount of free eIF- 2 available for reinitiation at uORFs 3 and 4, indirectly stimulating reinitiation at the GCN4 start site.

One well-established mechanism for reducing eIF-2 function in mammalian cells involves phosphorylation of the eIF- $2 \alpha$ subunit. This leads to tight binding of eIF-2B in an inactive complex with phosphorylated $\operatorname{eIF-2}(29,32,44)$. Interestingly, it was also reported that the guanine nucleotide exchange activity of eIF-2B decreases in response to amino acid starvation in rabbit reticulocytes (16) and that changes in the phosphorylation state of one of the subunits of eIF-2B alters its function (10). Given that GCN2, one of the positive regulators of $G C N 4$ translation, is a protein kinase (51), perhaps moderate phosphorylation of eIF- $2 \alpha$ or one of the subunits of the GCD1-containing complex is responsible for reducing the rate of reinitiation at uORFs 3 and 4 by one of the mechanisms described. Genetic studies indicate that the positive factor GCN3 functions downstream 
from GCN2 in the general control pathway (19). The fact that deletion of $G C N 3$ has no obvious phenotype under conditions of amino acid sufficiency (20) suggests that GCN3 is a regulatory subunit of the GCD1-containing complex that potentiates the inhibitory effects of GCN2-mediated phosphorylation on the function of the complex in amino acidstarved cells.

\section{ACKNOWLEDGMENTS}

We thank members of the Hinnebusch laboratory for their helpful comments during the course of this work. We also thank Janet Bushman, Thomas Donahue, Michael Mathews, and Charles Moehle for their helpful comments on the manuscript. Special thanks are extended to Brian Safer for his advice and comments on the manuscript, Richard Singer and Gerald Johnston for providing the $P R T I$ plasmid, Kevin Struhl and David Hill for providing the GCDI plasmid, and Tom Donahue for the eIF- $2 \alpha$ and eIF-2 $\beta$ antibodies.

This work was done while A. M. Cigan held a National Research Council Research Associateship.

\section{REFERENCES}

1. Abastado, J. P., P. F. Miller, B. M. Jackson, and A. G. Hinnebusch. 1991. Suppression of ribosomal reinitiation at upstream open reading frames in amino acid-starved cells forms the basis for GCN4 translational control. Mol. Cell. Biol. 11:486-496.

2. Ahmad, M. F., N. Nasrin, A. C. Banerjee, and N. K. Gupta. 1985. Purification and properties of eukaryotic initiation factor 2 and its ancillary protein factor (Co-eIF-2A) from yeast Saccharomyces cerevisiae. J. Biol. Chem. 260:6955-6959.

3. Anthony, D. D., T. G. Kinzy, and W. C. Merrick. 1990. Affinity labeling of eukaryotic initiation factor and elongation factor 1 with GTP analogs. Arch. Biochem. Biophys. 281:157-162.

4. Boeke, J. D., F. LaCroute, and G. R. Fink. 1984. A positive selection for mutants lacking orotidine-5'-phosphate decarboxylase activity in yeast: 5-fluoro-orotic acid resistance. Mol. Gen. Genet. 197:345-346.

5. Bradford, M. M. 1976. A rapid and sensitive method for the quantitation of microgram quantities of protein utilizing the principle of protein-dye binding. Anal. Biochem. 72:248-254.

6. Burke, R. L., P. Tekamp-Olson, and R. Najarian. 1983. The isolation, characterization, and sequence of the pyruvate kinase gene of Saccharomyces cerevisiae. J. Biol. Chem. 258:21932201.

6a.Cigan, A. M., and A. G. Hinnebusch. Unpublished data.

7. Cigan, A. M., E. K. Pabich, and T. F. Donahue. 1988. Mutational analysis of the HIS4 translational initiator region in Saccharomyces cerevisiae. Mol. Cell. Biol. 8:2964-2975.

8. Cigan, A. M., E. K. Pabich, L. Feng, and T. F. Donahue. 1989. Yeast translation initiation suppressor sui2 encodes the alpha subunit of eukaryotic initiation factor 2 and shares identity with the human alpha subunit. Proc. Natl. Acad. Sci. USA 86:2784 2788.

9. De Benedetti, A., and C. Baglioni. 1983. Phosphorylation of initiation factor eIF $2 \alpha$, binding of mRNA to $48 \mathrm{~S}$ complexes, and its reutilization in initiation of protein synthesis. J. Biol. Chem. 258:14556-14562.

10. Dholakia, J. N., and A. J. Wahba. 1988. Phosphorylation of the guanine nucleotide exchange factor from rabbit reticulocytes regulates its activity in polypeptide chain initiation. Proc. Natl. Acad. Sci. USA 85:51-54.

11. Dieckmann, C. L., and A. Tzagoloff. 1985. Assembly of the mitochondrial membrane system. J. Biol. Chem. 260:1513-1520.

12. Donahue, T. F., A. M. Cigan, E. K. Pabich, and B. CastilhoValavicius. 1988. Mutations at a $\mathrm{Zn}$ (II) finger motif in the yeast eIF- $2 \beta$ gene alter ribosomal start-site selection during the scanning process. Cell 54:621-632.

13. Feinberg, A. P., and B. Vogelstein. 1984. Addendum: a technique for radiolabeling DNA restriction endonuclease fragments to high specific activity. Anal. Biochem. 137:266-267.

14. Feinberg, B., C. S. McLaughlin, and K. Moldave. 1982. Analysis of temperature-sensitive mutant $t s 187$ of Saccharomyces cerevisiae altered in a component required for the initiation of protein synthesis. J. Biol. Chem. 257:10846-10851.

14a.Foiani, M., A. M. Cigan, C. J. Paddon, S. Harashima, and A. G. Hinnebusch. 1991. GCD2, a translational repressor of the GCN4 gene, has a general function in the initiation of protein synthesis in Saccharomyces cerevisiae. Mol. Cell. Biol. 11:3203-3216.

15. Gross, M., R. Redman, and D. A. Kaplansky. 1985. Evidence that the primary effect of phosphorylation of eukaryotic initiation factor 2 alpha in rabbit reticulocyte lysate is inhibition of the release of eukaryotic initiation factor-2. GDP from 60S ribosomal subunits. J. Biol. Chem. 260:9491-9500.

16. Gross, M., and M. S. Rubino. 1989. Regulation of eukaryotic initiation factor-2B by polyamines and amino acid starvation in rabbit reticulocyte lysate. J. Biol. Chem. 264:21879-21884.

17. Gross, M., M. Wing, C. Rundquist, and M. S. Rubino. 1987. Evidence that phosphorylation of eIF-2( $\alpha$ ) prevents the eIF-2Bmediated dissociation of eIF-2 . GDP from the 60S subunit of complete initiation complexes. J. Biol. Chem. 262:6899-6907.

18. Hanic-Joyce, P. J., R. A. Singer, and G. C. Johnston. 1987. Molecular characterization of the yeast PRTI gene in which mutations affect translation initiation and regulation of cell proliferation. J. Biol. Chem. 262:2845-2851.

19. Hannig, E. H., N. P. Williams, R. C. Wek, and A. G. Hinnebusch. 1990. The translational activator GCN3 functions downstream from GCN1 and GCN2 in the regulatory pathway that couples GCN4 expression to amino acid availability in Saccharomyces cerevisiae. Genetics 126:549-562.

20. Hannig, E. M., and A. G. Hinnebusch. 1988. Molecular analysis of $G C N 3$, a translational activator of $G C N 4$ : evidence for posttranslational control of GCN3 regulatory function. Mol. Cell. Biol. 8:4808-4820.

21. Harashima, S., E. M. Hannig, and A. G. Hinnebusch. 1987. Interactions between positive and negative regulators of GCN4 controlling gene expression and entry into the yeast cell cycle. Genetics 117:409-419.

22. Harashima, S., and A. G. Hinnebusch. 1986. Multiple GCD genes required for repression of GCN4, a transcriptional activator of amino acid biosynthetic genes in Saccharomyces cerevisiae. Mol. Cell. Biol. 6:3990-3998.

23. Hartwell, L. H., and C. S. McLaughlin. 1969. A mutant of yeast apparently defective in the initiation of protein synthesis. Proc. Natl. Acad. Sci. USA 62:468-474.

24. Hill, D. E., and K. Struhl. 1988. Molecular characterization of $G C D 1$, a yeast gene required for general control of amino acid biosynthesis and cell-cycle initiation. Nucleic Acids Res. 16: 9253-9265.

25. Hinnebusch, A. G. 1985. A hierarchy of trans-acting factors modulate translation of an activator of amino acid biosynthetic genes in yeast. Mol. Cell. Biol. 5:2349-2360.

26. Hinnebusch, A. G. 1988. Mechanisms of gene regulation in the general control of amino acid biosynthesis in Saccharomyces cerevisiae. Microbiol. Rev. 52:248-273.

27. Hinnen, A., J. B. Hicks, and G. R. Fink. 1978. Transformation of yeast. Proc. Natl. Acad. Sci. USA 75:1929-1933.

28. Ito, H., Y. Fukada, K. Murata, and A. Kimura. 1983. Transformation of intact yeast cells treated with alkali cations. J. Bacteriol. 153:163-168.

29. Konieczny, A., and B. Safer. 1983. Purification of the eukaryotic initiation factor 2-eukaryotic initiation factor $2 \mathrm{~B}$ complex and characterization of its guanine nucleotide exchange activity during protein synthesis initiation. J. Biol. Chem. 258:34023408 .

30. Laemmli, U. 1970. Cleavage of structural proteins during the assembly of the head of bacteriophage T4. Nature (London) 227:680-685.

31. Martin, T. E., and L. H. Hartwell. 1970. Resistance of active yeast ribosomes to dissociation by $\mathrm{KCl}$. J. Biol. Chem. 245: 1504-1508.

32. Matts, R., D. Levin, and I. London. 1983. Effect of phosphorylation of the alpha-subunit of eukaryotic initiation factor 2 on the function of reversing factor in the initiation of protein synthesis. Proc. Natl. Acad. Sci. USA 80:2559-2563. 
33. Moldave, K. 1985. Eukaryotic protein synthesis. Annu. Rev. Biochem. 54:1109-1149.

34. Moldave, K., and C. S. McLaughlin. 1988. The analysis of temperature-sensitive mutants of Saccharomyces cerevisiae altered in components required for protein synthesis, p. 271-281. In M. F. Tuite (ed.), Genetics of translation. Springer-Verlag, Berlin.

35. Mueller, P. P., S. Harashima, and A. G. Hinnebusch. 1987. A segment of GCN4 mRNA containing the upstream AUG codons confers translational control upon a heterologous yeast transcript. Proc. Natl. Acad. Sci. USA 84:2863-2867.

36. Mueller, P. P., and A. G. Hinnebusch. 1986. Multiple upstream AUG codons mediate translational control of GCN4. Cell 45: 201-207.

37. Paddon, C. J., E. M. Hannig, and A. G. Hinnebusch. 1989. Amino acid sequence similarity between GCN3 and GCD2, positive and negative translational regulators of GCN4: evidence for antagonism by competition. Genetics 122:551-559.

38. Paddon, C. J., and A. G. Hinnebusch. 1989. gcdl2 mutations are gcn3-dependent alleles of $G C D 2$, a negative regulator of $G C N 4$ in the general amino acid control of Saccharomyces cerevisiae. Genetics 122:543-550.

39. Parent, S. A., C. M. Fenimore, and K. A. Bostian. 1985. Vector systems for the expression, analysis and cloning of DNA sequences in $S$. cerevisiae. Yeast 1:83-138.

40. Peterson, D. T., W. C. Merrick, and B. Safer. 1979. Binding and release of radiolabeled eukaryotic initiation factors 2 and 3 during $80 \mathrm{~S}$ initiation complex formation. J. Biol. Chem. 254: 2509-2519.

41. Rowlands, A. G., K. S. Montine, E. C. Henshaw, and R. Panniers. 1988. Physiological stresses inhibit guanine-nucleotide-exchange factor in Ehrlich cells. Eur. J. Biochem. 175:9399.

41a.Safer, B. Personal communication.

42. Salimans, M., H. Goumans, H. Amesz, R. Beene, and H. Voorma. 1984. Regulation of protein synthesis in eukaryotes. Mode of action of eRF, an eIF-2-recycling factor from rabbit reticulocytes in GDP/GTP exchange. Eur. J. Biochem. 145:9198.

43. Sherman, F., G. R. Fink, and C. W. Lawrence. 1974. Methods of yeast genetics. Cold Spring Harbor Laboratory, Cold Spring Harbor, N.Y.
44. Siekierka, J., V. Manne, and S. Ochoa. 1984. Mechanism of translational control by partial phosphorylation of the alpha subunit of eukaryotic initiation factor 2. Proc. Natl. Acad. Sci. USA 81:352-356.

45. Thomas, N. S. B., R. L. Matts, D. H. Levin, and I. M. London. 1985. The 60S ribosomal subunit as a carrier of eukaryotic initiation factor 2 and the site of reversing factor activity during protein synthesis. J. Biol. Chem. 260:9860-9866.

46. Thomas, N. S. B., R. Matts, R. Petryshyn, and I. London. 1984. Distribution of reversing factor in reticulocyte lysates during active protein synthesis and on inhibition by heme deprivation or double-stranded RNA. Proc. Natl. Acad. Sci. USA 81:69987002.

47. Towbin, H., T. Staehelin, and J. Gordon. 1979. Electrophoretic transfer of proteins from polyacrylamide gels to nitrocellulose: procedure and some applications. Proc. Natl. Acad. Sci. USA 76:4350-4354.

48. Tzamarias, D., D. Alexandraki, and G. Thireos. 1986. Multiple cis-acting elements modulate the translational efficiency of GCN4 mRNA in yeast. Proc. Natl. Acad. Sci. USA 83:48494853.

49. Tzamarias, D., I. Roussou, and G. Thireos. 1989. Coupling of GCN4 mRNA translational activation with decreased rates of polypeptide chain initiation. Cell 57:947-954.

50. Warner, J. R., G. Mitra, W. F. Schwindinger, M. Studeny, and H. M. Fried. 1985. Saccharomyces cerevisiae coordinates accumulation of yeast ribosomal proteins by modulating mRNA splicing, translational initiation, and protein turnover. Mol. Cell. Biol. 5:1512-1521.

51. Wek, R. C., B. M. Jackson, and A. G. Hinnebusch. 1989. Juxtaposition of domains homologous to protein kinases and histidyl-tRNA synthetases in GCN2 protein suggests a mechanism for coupling GCN4 expression to amino acid availability. Proc. Natl. Acad. Sci. USA 86:4579-4583.

52. Williams, N. P., A. G. Hinnebusch, and T. F. Donahue. 1989. Mutations in the structural genes for eukaryotic initiation factors $2 \alpha$ and $2 \beta$ of Saccharomyces cerevisiae disrupt translational control of GCN4 mRNA. Proc. Natl. Acad. Sci. USA 86:7515-7519.

53. Wolfner, M., D. Yep, F. Messenguy, and G. R. Fink. 1975. Integration of amino acid biosynthesis into the cell cycle of Saccharomyces cerevisiae. J. Mol. Biol. 96:273-290. 